\title{
Neuropeptide Routing in the Bag Cells: Kinetic Differences in the Appearance of Newly Labeled Peptides in Transport and Secretion
}

\author{
S. Arch, A. Linstedt, ${ }^{1}$ G. Whitney, P. Teal, ${ }^{2}$ and T. Smock ${ }^{3}$ \\ Biological Laboratories, Reed College, Portland, Oregon 97202
}

The bag cell neurons of Aplysia synthesize and secrete several peptides. Some of these, in addition to the egg-laying hormone (ELH), are strongly implicated in the various alterations of central neuronal activity that accompany an electrical discharge of the bag cells. Thus, the secreted peptides appear to play a variety of roles in the animal's physiology. We have been interested in the intracellular mechanisms that precede peptide secretion from the bag cells because of the evidence that most, if not all, of these peptides are derived from a common precursor. Our objective has been to determine if presumed products of this precursor are processed coordinately following their synthesis. We have concentrated on two peptides (ELH and the acidic peptide, AP) because they are most easily identified in our analytical systems. On pulse-chase radiolabeling of the cells in vitro, we found that labeled AP appears before labeled ELH in axonal transport. This observation is not easily accounted for by the assumption, taken from studies of other peptide-secreting cells, that a precursor to both peptides is loaded into secretory granules before further processing ensues. Since the initial disproportion in the representation of the peptides in transport is no longer detectable at long chase times (18 and $24 \mathrm{hr}$ ), we examined the possibilities that ELH production is delayed relative to that of AP or that AP is degraded more rapidly than ELH. No evidence was found for either process. The disproportion between the newly labeled peptides in transport was evident on analysis of the medium bathing bag cells depolarized after $24 \mathrm{hr}$ of chase. In addition to indicating that neither delayed production nor degradation is a major process affecting the peptide stoichiometry in transport, the secretion results appeared to show the existence of a queuing mechanism that constrains granule intermixing at secretory terminals. Finally, by analysis of single-cell peptide contents, we sought to determine if individual cells specialize in production of one or the other peptide. All the cells we assayed had produced both ELH and AP. Hence, we interpret our results to be consistent with an inference that ELH and AP are produced in a manner that leads to their independent inclusion in secretory granules.

The bag cell neurons of Aplysia californica were the first peptidergic neurons demonstrated to produce their characteristic secretory product, the egg-laying hormone (ELH), by way of a larger precursor protein (Arch, 1972b). It was subsequently de-

\footnotetext{
Received July 27, 1984; revised Sept. 20, 1985; accepted Oct. 15, 1985.

We wish to thank Dr. Arnold Eskin for helpful comments on an earlier version of this manuscript and Mr. Gene Dannen for his technical assistance during some of the work reported here. This project was supported by funds from U.S. Public Health Service grants NS-11149 and RR-07168.

Correspondence should be addressed to Dr. Arch at the above address

1 Present address: Department of Neuroscience, University of California School of Medicine, San Francisco, CA 94143

2 Present address: Veterans Administration Medical Center, Immunology Research, Box 1034, Portland, OR 97207.

${ }^{3}$ Present address: Department of Psychology, University of Colorado, Boulder, CO 80309

Copyright (c) 1986 Society for Neuroscience $0270-6474 / 86 / 061545-08 \$ 02.00 / 0$
}

termined that a second peptide of approximately the same size, but considerably different isoelectric point, the acidic peptide (AP), was also synthesized, transported, and secreted by these neurons (Arch, 1981; Arch et al., 1976a, b). The kinetics of appearance of these two peptides in the cell after pulse labeling led to the inference that they are derived from a common precursor. More recently, peptide mapping (Berry, 1981; Berry et al., 1981) and gene sequence (Mahon et al., 1985; Scheller et al., 1984) studies have supported this inference. There is also structural and functional evidence for the existence of three smaller peptides produced from the precursor sequence (Rothman et al., 1985; Scheller et al., 1983, 1984).

Although the precursor molecule appears to give rise to several peptides for which there is some form of physiological evidence of secretion, these sequences comprise less than half the precursor. Both earlier (Arch, 1972b; Arch et al., 1976a, b) and more recent (Berry, 1981; Yates and Berry, 1984) studies indicate that an initial cleavage of the precursor results in the production of a substantial fragment that remains in the cell somata and turns over slowly (cf. Loh et al., 1975). The remaining portion of the precursor appears to undergo further processing with transport to secretory terminals reducing its representation in the cell somata. It appears, therefore, that the initial stage of precursor processing precedes the formation of secretory granules.

The locations of further processing of the precursor fragment containing the secreted peptides is not known. Yates and Berry (1984) suggest, from studies using monensin-intoxicated cells, that an intermediate containing both AP and ELH may be inserted into secretory granules before further conversion occurs This would be consistent with the evidence for intragranular precursor conversion from studies of the production of neurophysins and their associated nonapeptide hormones in the magnocellular neurons of rats (Gainer et al., 1977). Similarly, precursor conversion, or the presence of conversion-competent enzymatic activities, have been found in a variety of peptidesecreting, nonneuronal cells (Fletcher et al., 1981; Glembotski, 1981; Gumbiner and Kelly, 1981; Hook and Loh, 1984). The studies reported in this paper were undertaken to determine if ELH and AP are likewise produced within the neurosecretory granules of bag cell neurons. Since our initial results cast doubt on this mechanism, we have evaluated a variety of alternative hypotheses.

\section{Materials and Methods}

Aplysia californica were obtained at 3-week intervals from Alacrity Marine Biological Services (Redondo Beach, CA). They were maintained in a 165 gallon aquarium containing recirculated artificial sea water at $15^{\circ} \mathrm{C}$ and 34 parts per thousand. An overhead fluorescent light photocycle of $16 \mathrm{hr}$ light: $8 \mathrm{hr}$ dark was automatically controlled. All procedures described below were conducted at $15^{\circ} \mathrm{C}$ unless otherwise noted. All glass- and plastic-ware used in these studies was silanized.

The parietovisceral (abdominal) ganglion was removed from freshly killed animals, and the bag cell organs (BCO) with $1-2 \mathrm{~cm}$ lengths of 
connective nerves were dissected. After preincubation in ultrafiltered $(0.22 \mu \mathrm{m})$ artificial seawater for $4 \mathrm{hr}$, the BCO were transferred to a defined medium (Arch, 1972b) for radiolabel uptake. The incubation medium volume was $250 \mu \mathrm{l}$ and contained $25 \mu \mathrm{Ci}^{3} \mathrm{H}$-leucine (L-leucine $3,4,5-{ }^{3} \mathrm{H},>140 \mathrm{mCi} / \mathrm{mm}$, New England Nuclear, Boston, MA). Radiolabel incorporation was terminated after either 1 or $6 \mathrm{hr}$ by transfer of the BCO to a chase medium (Arch, 1972b) containing a 1000-fold excess of unlabeled leucine. Chase continued for various times as noted.

\section{Pulse-chase procedure}

For the pulse-chase studies, the $\mathrm{BCO}$ were removed from the chase medium, blotted dry, and frozen on dry ice. They were typically stored at $-25^{\circ} \mathrm{C}$ for $24 \mathrm{hr}$ or less before preparation and analysis. For the studies employing $\mathrm{I} \mathrm{hr}$ labeling pulses, a frozen $\mathrm{BCO}$ was homogenized and prepared for analysis as described below. In the series using $6 \mathrm{hr}$ pulses, the frozen $\mathrm{BCO}$ was thawed at $2^{\circ} \mathrm{C}$ on a thermoelectrically cooled microscope stage and then manually dissected into two samples under a dissecting microscope. One sample was obtained by making two transections approximately $1 \mathrm{~mm}$ apart along the root of the connective nerve immediately rostral to the cell cluster. This sample is enriched for bag cell neurites but is unlikely to contain cell bodies. The other sample was obtained by slitting the connective tissue capsule surrounding the bag cell cluster and gently extruding the cell somata. Each sample was immediately ground in $50 \mu \mathrm{l}$ of ice-cold, $0.1 \mathrm{M}$ acetic acid containing $100 \mu \mathrm{g} / \mathrm{ml}$ each of ovomucoid trypsin inhibitor, bacitracin, and N-A-P tosyl-lysine chloromethyl ketone (TLCK; Sigma Chemical Co., St. Louis). The homogenate was subsequently centrifuged at $10,000 \times g$ for 10 min at $4^{\circ} \mathrm{C}$. The resulting supernatant solution was removed and retained on ice while a second homogenization of the pellet in $50 \mu \mathrm{l}$ of the protease inhibitor supplemented acetic acid was performed. The second supernatant solution after centrifugation was pooled with the first and the combined volume was lyophilized in a vacuum centrifuge.

\section{Single-cell analysis}

A different postincubation procedure was used to obtain single bag cells for analysis. After $6 \mathrm{hr}, \mathrm{BCO}$ were transferred from the incubation medium to one containing $1 \mathrm{mM} \mathrm{Ca}^{2+}$ and elevated $\mathrm{Mg}^{2+}$ (Arch, 1972b) to suppress secretory activity. Thirty minutes later, the bag cell clusters were removed from the BCO. They were then transferred to fresh low$\mathrm{Ca}^{2+}$ medium containing $1 \mathrm{mg} / \mathrm{ml}$ collagenase (EC 3.4.24.3, Type IV, Sigma Chemicals). Enzyme treatment lasted for $3 \mathrm{hr}$ and was followed by a brief rinsing in the same medium devoid of collagenase. Single bag cell somata were then separated from the cell clusters under low-Ca ${ }^{2+}$ medium with glass needles. Each cell was taken up in a capillary tube with a minimum of surrounding medium $(1-3 \mu \mathrm{l})$ and transferred to a plastic microtubc containing $50 \mu \mathrm{l}$ of the acetic acid grinding medium previously described. The remaining bag cell cluster and three to five samples $\left(5 \mu \mathrm{l}\right.$ each) of the low-Ca ${ }^{2+}$ medium were similarly transferred to grinding medium and all tubes were frozen on crushed dry ice.

The residual cell clusters were subsequently homogenized manually, centrifuged for $10 \mathrm{~min}$ at $10,000 \times g\left(4^{\circ} \mathrm{C}\right)$, with the supernatant solution retained for analysis. The single cells and medium samples were thawed on ice, drawn into and expelled from a capillary tube, and frozen on dry ice. This freeze-thaw and mixing sequence was repeated three times. All samples were then lyophilized and held at $-25^{\circ} \mathrm{C}$ until analysis by isoelectric-focusing electrophoresis.

Analysis of the medium samples was performed to determine the extent to which the medium carried over with the single cells contributed to the electrophoresis pattern obtained. The results indicated that an upper limit of $15 \%$ of the total radiolabel detected in the single-cell samples could be ascribed to contamination from the medium. The distribution of radiolabel in the medium samples approximated that detected in the residual cell cluster samples and presumably represents leakage from cells damaged during single-cell dissection. No evidence of secretory discharge of peptides was detected.

\section{Isoelectric-focusing electrophoresis}

Isoelectric-focusing gels containing $\mathrm{pH}$ 3.5-10 ampholytes (LKB-Produkter, Bromma, Sweden) were prepared and run as previously described (Arch et al., 1976a). Following overnight extraction of the gels in two changes of $10 \%$ trichloroacetic acid (TCA), scintillation counting of sequential gel slices in Wilson's counting solution (Ward et al., 1969) was performed. Data retrieval, reduction, and graphical analysis were managed by computer.

\section{Neurosecretion procedure}

For studies of peptide secretion from the $\mathrm{BCO}$, the pulse-chase procedure described above was followed, but the chase interval was ended by transfer of the BCO to a $200 \mu \mathrm{l}$ vol of osmotically balanced medium containing 10 times the normal potassium concentration (Arch, 1972b) and supplemented with $1 \mathrm{~mm}$ TLCK. After $60 \mathrm{~min}$, the BCO were transferred to a rinse medium and held for variable periods before being challenged once again in high-potassium medium. The high-potassium medium, after removal of the $\mathrm{BCO}$, was lyophilized to remove ${ }^{3} \mathrm{H}_{2} \mathrm{O}$, redissolved in ultrapure water, centrifugally filtered through a Nylon 66 membrane filter, and injected into a reverse-phase $C_{18}$ column $(5 \mu \mathrm{m}$ spherical packing, $4.6 \times 25 \mathrm{~mm}$; Alltech Assoc., Deerfield, IL) connected to an high-pressure liquid chromatography (HPLC) system. The sample was eluted at ambient temperature with a programmed gradient starting at $100 \%$ aqueous $0.01 \mathrm{~m}$ ammonium acetate $(\mathrm{pH} 5.5)$ and ending at $70 \%$ ammonium acetate : $30 \%$ acetonitrile. Sequential fractions were collected at a rate of $1 \mathrm{ml} / \mathrm{min}$ and sampled for analysis by scintillation counting. The retention times for ELH and AP were determined by calibration of the column with previously purified radiolabeled peptides.

\section{Results}

Our initial experiments were designed to determine if recently synthesized ELH and AP appcar in axonal transport coordinately. We chose to follow the appearance of AP and ELH as indicators of the final stages of precursor processing because they are known to be transported by a colchicine-sensitive process and secreted in response to depolarization (Arch, 1972a; Arch et al., 1976b; Kupfermann, 1972; Loh et al., 1975; Stuart et al., 1980). Moreover, because of their relatively high leucine content (Chiu et al., 1979; Scheller et al., 1983) and dissimilar isoelectric points (Arch et al., 1976a), radiolabeling and isoelectric focusing give clear indications of their presence in samples of interest (e.g., Fig. 1, top). Although neither the pI 9.3 (ELH) nor the pI 4.8 (AP) peak of radiolabel on IEF gels is pure with respect to contaminating radiolabeled species, elution from IEF and re-electrophoresis on SDS-PAGE, or chromatography on HPLC, indicates $80 \%$ or more of the TCA-precipitable, leucine-radiolabel is in a single species at each isoelectric point (Arch et al., 1976a; and unpublished observations).

If it is assumed that these two species are components of a common precursor and that this precursor, or a common intermediate, is converted intragranularly, the two peptides should appear in transport with a fixed stoichiometry. Consequently, we allowed $\mathrm{BCO}$ to incorporate ${ }^{3} \mathrm{H}$-leucine for $6 \mathrm{hr}$ and then prepared soma and neurite samples for assay by IEF. The 6-hr labeling period was chosen because earlier studies (Arch et al., $1976 \mathrm{~b}$ ) indicated that this much time was required for biosynthetically labeled protein to appear in axonal transport. Figure 1 illustrates an example of a $6 \mathrm{hr}$ label: $15 \mathrm{~min}(0 \mathrm{hr})$ chase sample. It is evident that the peptides of interest are both abundantly present in labeled form at this time in the soma sample and that labeled AP is already present in the neurites. As can be seen in Figure 2, the labeled peptides continue to accumulate, relative to other labeled and precipitable species, in the neurite sample with increasing time after the end of the radiolabeling period. The precipitable radiolabel not attributable to either peptide in these samples, i.e., the denominator in the specific activity calculation, shows no trend across the series. The lowest value $(1171 \pm 146 \mathrm{cpm}$, mean $\pm \mathrm{SEM})$ was at $6 \mathrm{hr}$ and the highest $(2321 \pm 362$ and $2324 \pm 757 \mathrm{cpm})$ were at 0 and 24 hr.

It is notable that labeled AP appears in its native form in the neurites before labeled ELH. The course of the changing relationship between newly synthesized ELH and AP in transport is shown in Figure 3. If we take the radiolabel stoichiometry between the two peptides in the soma samples at the end of the incubation period ( $0 \mathrm{hr}$ chase) to be an indication of their synthetic stoichiometry, then it appears that the peptides entering transport at the earlier times after the end of radiolabel incor- 



Figure 1. Two profiles illustrate the distribution of labeled peptides from bag cell somata and neurites after separation by isoelectric focusing electrophoresis. The peaks labeled $A$ and $E$, respectively, represent AP and $\mathrm{ELH}$ and occur at $\mathrm{pH}$ positions of approximately 4.8 and 9.3. The two gels were prepared from a single BCO rinsed $15 \mathrm{~min}$ after a $6 \mathrm{hr}$ pulse labeling in ${ }^{3} \mathrm{H}$-leucine. The relative quantities of the two peptides present in labeled form in the neurites is very different from their synthetic stoichiometry as seen in the cell bodies.

poration do not reflect this proportionality. On the grounds that this unexpected difference between soma and initial neurite stoichiometries may provide some insight into the processes of peptide production, we attempted to investigate this transport disproportion further.

The temporal change in peptide stoichiometry is evident spatially along the neurites at a single chase time (Fig. 4). The more distal neurite samples show relatively more labeled AP than the more proximal. It is interesting to note that the distal samples show a prominent neutral peak of radiolabel in addition to those for the peptides (see also Fig. 1, bottom).

To examine the possibility that the latency in ELH appearance in the neurites is the result of a slow conversion of an ELHcontaining intermediate, we assayed the peptide content of the medium surrounding the BCO after thcy had been depolarized. As is evident in Figure 5, even at $24 \mathrm{hr}$ after incubation, when the neurite $\mathrm{ELH}: \mathrm{AP}(\mathrm{E}: \mathrm{A})$ ratio is at the same value as the initial soma ratio (Fig. 3), little labeled ELH is secreted on an initial depolarization. However, when a second depolarization is imposed, labeled ELH appcars in quantity. The results for six replicates of this procedure are summarized in Table 1 and show that the changes between first and second secretion challenges are statistically significant for only the materials located at the

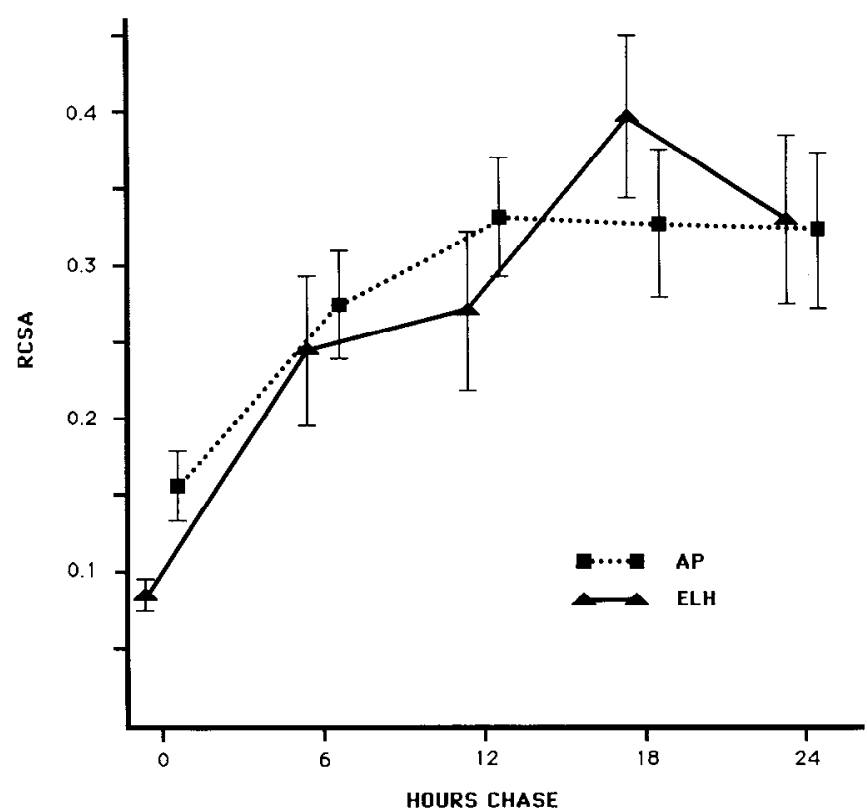

Figure 2. Radiochemical specific activity $(R C S A)$ of the two peptides in the neurite fractions is plotted as a function of chase interval. ELH and AP were identified at their isoelectric points on electrophoretic gels and the counts per minute (cpm) in threc contiguous gel slices at the respective $\mathrm{p} I \mathrm{~s}$ were summed. The calculation of RCSA was made by dividing the summed $\mathrm{cpm}$ for each peptide by the total $\mathrm{cpm}$ in the gel after subtraction of the contribution from the other peptide. The values shown are means $( \pm \mathrm{SEM})$ of 5-10 individual determinations at each time point.

retention times characterized for AP and ELH with this elution system. Thus, it seems improbable that the gradual change in representation of ELH in the neurite samples is the result of a slow production of the peptide from some other form that pre-

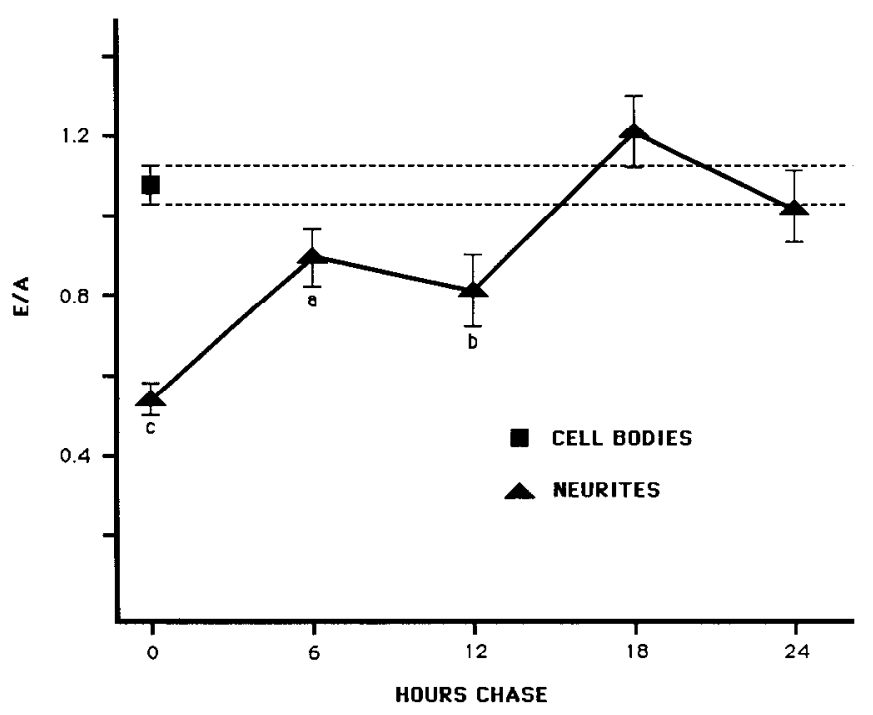

Figure 3. Mean $( \pm \mathrm{SEM})$ ratios of radiolabel in ELH to that in AP at various durations of chase following a $6 \mathrm{hr}$ labeling period are shown for rostral neurites of the bag cells. These ratios can be compared to the synthetic stoichiometry measured as the cell body ratio calculated at 0 $\mathrm{hr}$ chase and represented with dashed lines. These data were compiled from between 5 and 10 BCO assayed by isoelectric-focusing electrophoresis at each time point. The differences between the neurite ratios and that of the cell bodies were tested with Student's $t$ test. A pooled variance modification for small sample sizes was used (Dowdy and Wearden, 1983). $a, p<0.025 ; b, p<0.01 ; c, p<0.005$. 

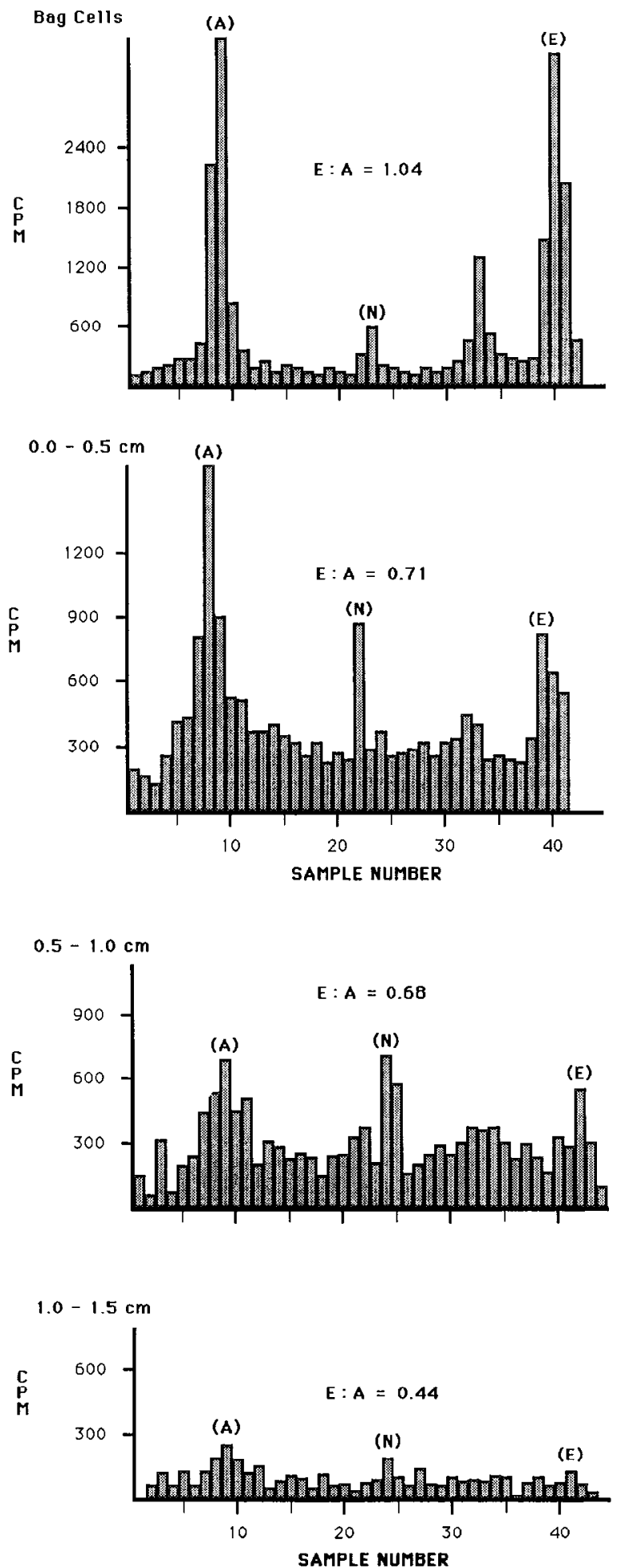

Figure 4. Relative quantities of labeled peptides in transport, as a function of distance from the cell bodies at $6 \mathrm{hr}$ of chase after a $6 \mathrm{hr}$ period of labeling, are shown in this set of IEF profiles. The BCO was removed from the chase medium and frozen on a microscope slide over dry ice. The connective nerves were gently stretched during freezing so that sequential transections could be made at the indicated levels rostral to the cell cluster. This example is one of a series of eight BCO sampled at various chase times. As would be expected (see Fig. 3), the difference between cell body and rostral neurite peptide ratios is more evident with shorter durations of chase. The positions of acidic peptide $(A)$, a neutral species $(N)$, and ELH $(E)$ are indicated. Note that the ordinate scale for the neurite samples differs from that for the cell bodies.
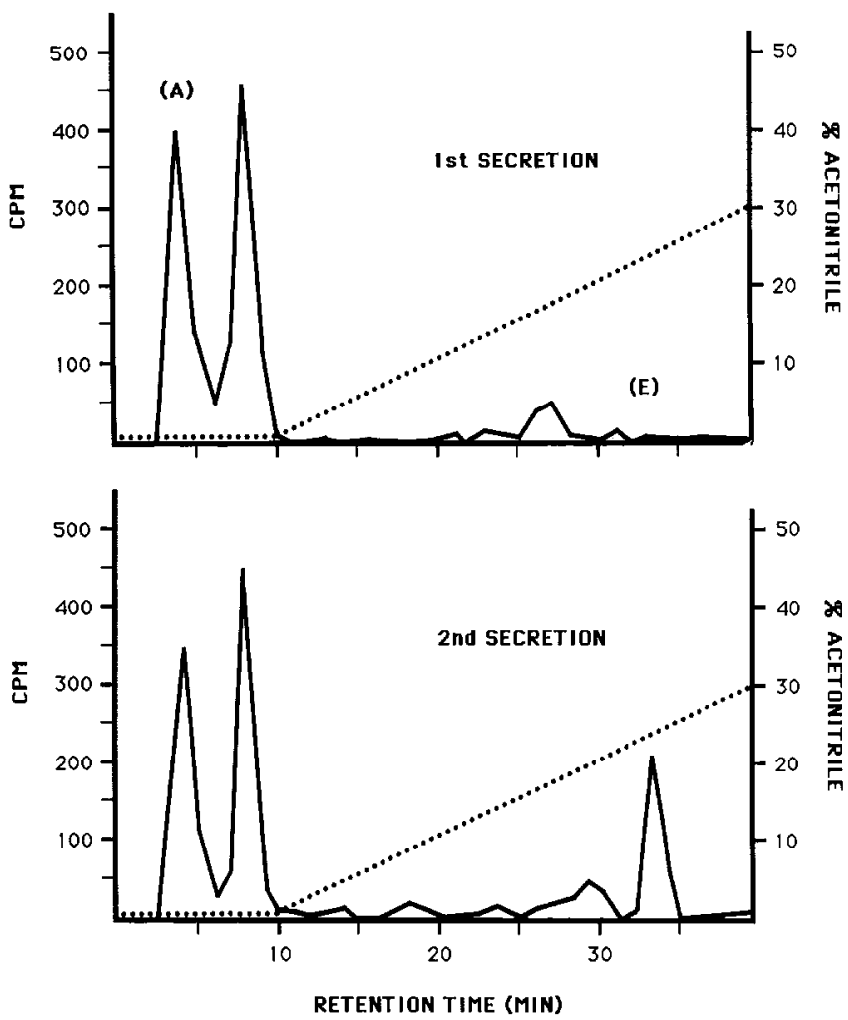

Figure 5. A, Distribution of radiolabel in the eluate $(1 \mathrm{ml} / \mathrm{min})$ from an RP-HPLC separation of $100 \mu$ l of high-potassium medium is shown. This is a first-secretion challenge of a pair of BCO after $24 \mathrm{hr}$ of chase following a $6 \mathrm{hr}$ pulse labeling. The first major peak $(A)$ on the abscissa is the column void with over $70 \%$ of the leucine radiolabel contained in AP. The second peak is ${ }^{3} \mathrm{H}$-leucine. The position of ELH elution is indicated $(E) . B$, The RP-HPLC separation of the medium from a second-secretion challenge is shown for the same tissue. This challenge was presented $4 \mathrm{hr}$ after the first challenge (illustrated above). The apparent staging of secretion according to labeled peptide arrival time at the terminal is cvidenced by the appreciable increase in labeled ELH recovered after this second depolarization.

viously entered the neurites. The apparent preponderance of labeled AP in early transport seems to be sustained so that the first labeled material secreted reproduces a relative AP abundance over ELH.

Newly arriving secretory granules must not intermix freely with those already present. It is as though there were some sort of mechanism that constrains the granules in relation to the active sites of secretion. We, therefore, attempted to determine

\begin{tabular}{lll}
\hline $\begin{array}{l}\text { Table 1. Radiolabeled species in superfusates of sequential } \\
\text { secretions }\end{array}$ \\
$\begin{array}{lll}\text { Retention } \\
\text { time } \\
\text { (min) }\end{array}$ & $\begin{array}{l}\text { First secretion } \\
\text { (cpm } \pm \text { SEM) }\end{array}$ & $\begin{array}{l}\text { Second secretion } \\
\text { (cpm } \pm \text { SEM) }\end{array}$ \\
\hline $4-5^{a}$ & $1467 \pm 175$ & $820 \pm 163^{d}$ \\
$6-7^{b}$ & $390 \pm 76$ & $154 \pm 25$ \\
$15-18$ & $208 \pm 78$ & $147 \pm 18$ \\
$20-21$ & $158 \pm 41$ & $72 \pm 38$ \\
$25-28$ & $248 \pm 86$ & $125 \pm 40$ \\
$33-35^{c}$ & $68 \pm 25$ & $590 \pm 232^{d}$ \\
\hline
\end{tabular}

${ }^{a}$ Retention time for AP.

${ }^{b}$ Retention time for ${ }^{3} \mathrm{H}-\mathrm{L}$ eu.

'Retention time for ELH.

${ }^{d}$ Count rate different from first secretion value at $p<0.05$ (two-tailed $t$ test with pooled variance). 

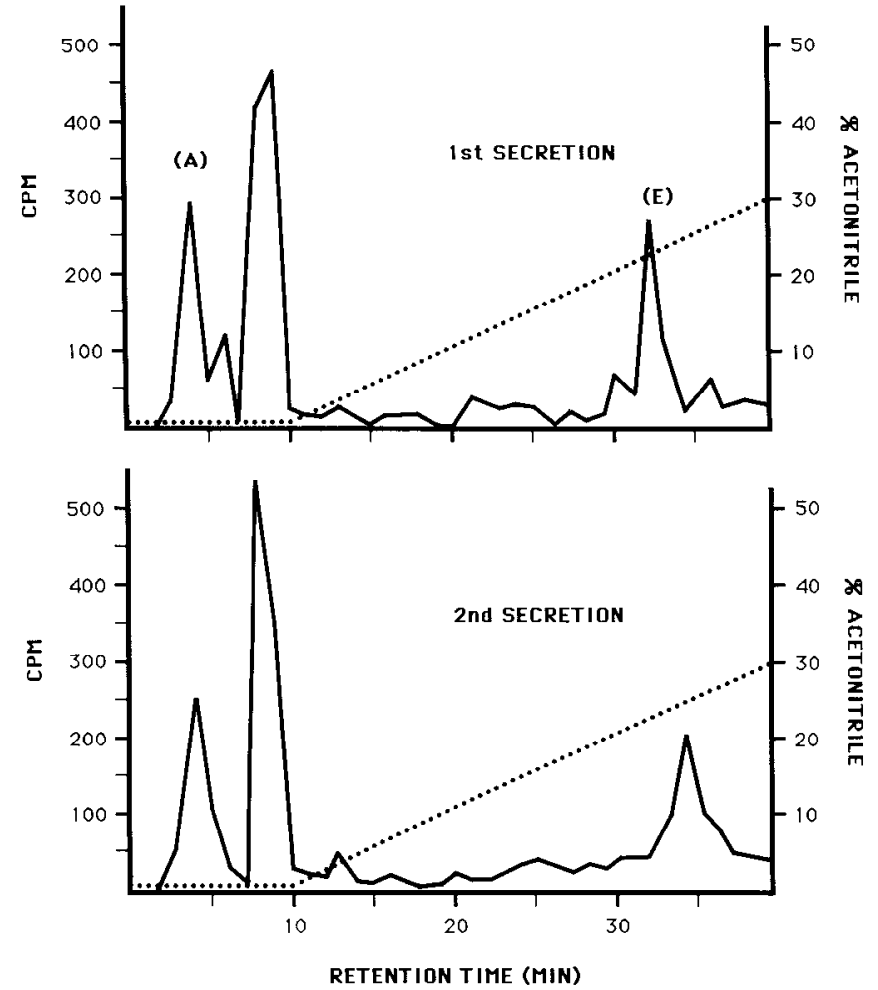

Figure 6. A, This first-secretion challenge was performed and assayed in the same way as described for Figure 4, except that the BCO was exposed to colchicine $(5 \mathrm{~mm})$ for $3 \mathrm{hr}$ immediately preceding the depolarization. A substantial amount of labeled ELH is secreted under these conditions. $B$, Result of the second-secretion challenge posed to the same $\mathrm{BCO}$ is shown.

if fibrous organelles play any role in maintenance of the neurosecretory granule "queue." When $\mathrm{BCO}$ are exposed to either colchicine (5 mM) or procaine $(0.1 \mathrm{~mm})$ (Nicholson et al., 1976) for $3 \mathrm{hr}$ after a $24 \mathrm{hr}$ chase and then stimulated to secrete, both AP and ELH are secreted in approximately the stoichiometry expected from their representation in the neurites (Fig. 6). Thus, disruption of the polymerization equilibria for microtubules and other fibrous organelles affects the apparent staging of secretion of newly synthesized AP and ELH.

Labeled AP may appear in transport earlier because its production from a precursor form in the cell bodies precedes that of ELH. To examine this possibility, we reduced the radiolabel incubation time from 6 to $1 \mathrm{hr}$. Earlier studies have shown that the initial precursor has a half-life of about $45 \mathrm{~min}$ (Arch, 1972b, 1976); thus, we reasoned that a latency between the subsequent production of AP and ELH would be more evident with the shorter labeling pulse. The results of this study are summarized in Figure 7. If production of AP occurred substantially earlier than that of ELH, we would have expected the ratio values to display a positive slope over the chase interval. Although the regression line for these data has a positive slope $\left(6.38 \times 10^{-5}\right)$, it is not significantly different from zero $(p=0.80)$; hence, if AP is being produced earlier than ELH, the latency is too short to be resolved by these methods.

An alternative possibility to account for the earlier appearance of AP in transport could be biochemical heterogeneity among the bag cells. If the cells "specialize" in the production of one or the other of the peptides of interest, as is the case for POMC products in the anterior and intermediate lobes of the mammalian pituitary (Herbert et al., 1981), the apparent temporal difference in the production of ELH and AP could be ascribed either to kinetic differences in precursor degradation or to the

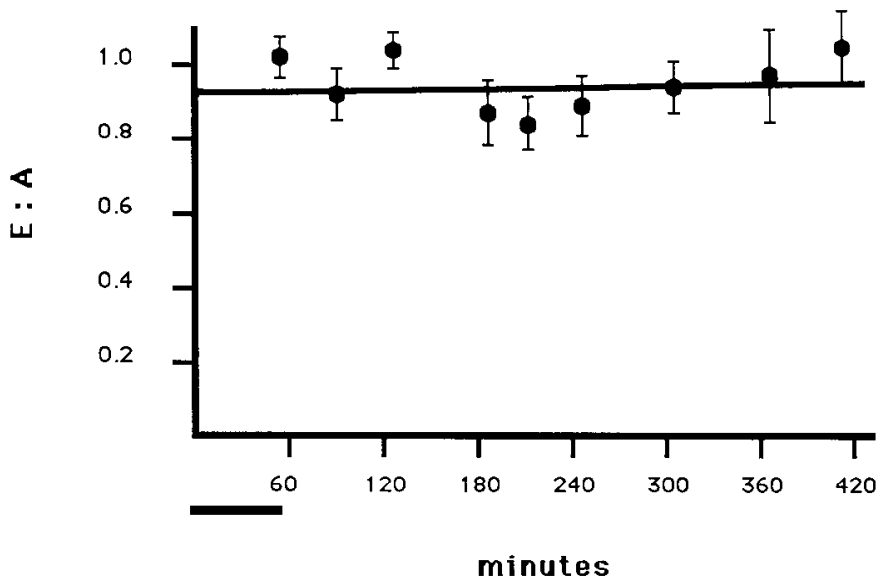

Figure 7. Mean E:A ratio ( \pm SEM) determined for 6-10 BCO at each point is shown as a function of chase time following a $60 \mathrm{~min}$ incubation (horizontal bar) of the tissue in ${ }^{3} \mathrm{H}$-leucine. The least-squares regression line fit to the data is shown.

location of the two cell types relative to the region from which the neurites were sampled. To test this possibility, we labeled $\mathrm{BCO}$ for $6 \mathrm{hr}$ and then manually recovered single-cell somata after a 3-hr postincubation in collagenase-containing medium. Examples of isoelectric-focusing electrophoresis gel profiles obtained from single cells are presented in Figure 8. It is evident that single cells produce both peptides at their native isoelectric points; thus, heterogeneity among bag cells to the extent that they produce only one or the other peptide is not apparent. The results of this study are summarized in Figure 9. This summary supports the inference drawn from the individual cases but also indicates substantial variation around the modal ratio value.

Two measures were taken to account for introduction of sample and methodological biases in the single-cell analyses. For the graphical presentation, normalization of the single-cell peptide ratios was performed by calculating the difference between the single-cell E:A ratio and that of the residual cell cluster from which the cell was removed. After this manipulation, if each cell in a cluster were essentially identical to every other, all cases would be logged at 0 on the abscissa. To control for methodological variations, labeled cell clusters were homogenized, assayed for radiolabel content, made up into aliquots to produce volumes and count rates comparable to those encountered with single cells, and then taken through the same sample preparation procedures as used with the single cells. Ratio difference calculations for 10 such samples from two different clusters displayed a range of values that would be included within the width of a single bar on the abscissa. It appears therefore that the variation displayed in this group of single cells is not a consequence of those aspects of tissue or procedural variability over which we have control. That there is a skew toward a relative excess of labeled ELH may be explained by the duration of the postincubation period. Some cells may have exported relatively more AP than the population average. Whether this explanation can be extended to the more extreme cases is not clear. The possibility that some cells may be expressing more than one precursor sequence (Scheller et al., 1982; cf. Mahon et al., 1985) cannot be excluded in our analysis. Indeed, the indication of a secondary mode at approximately +0.5 on the abscissa could represent a contribution from the products of such an additional precursor.

\section{Discussion}

These studies were undertaken to gain further information about the location of the major posttranslational processing steps in the generation of the secretory peptides characteristic of the bag 

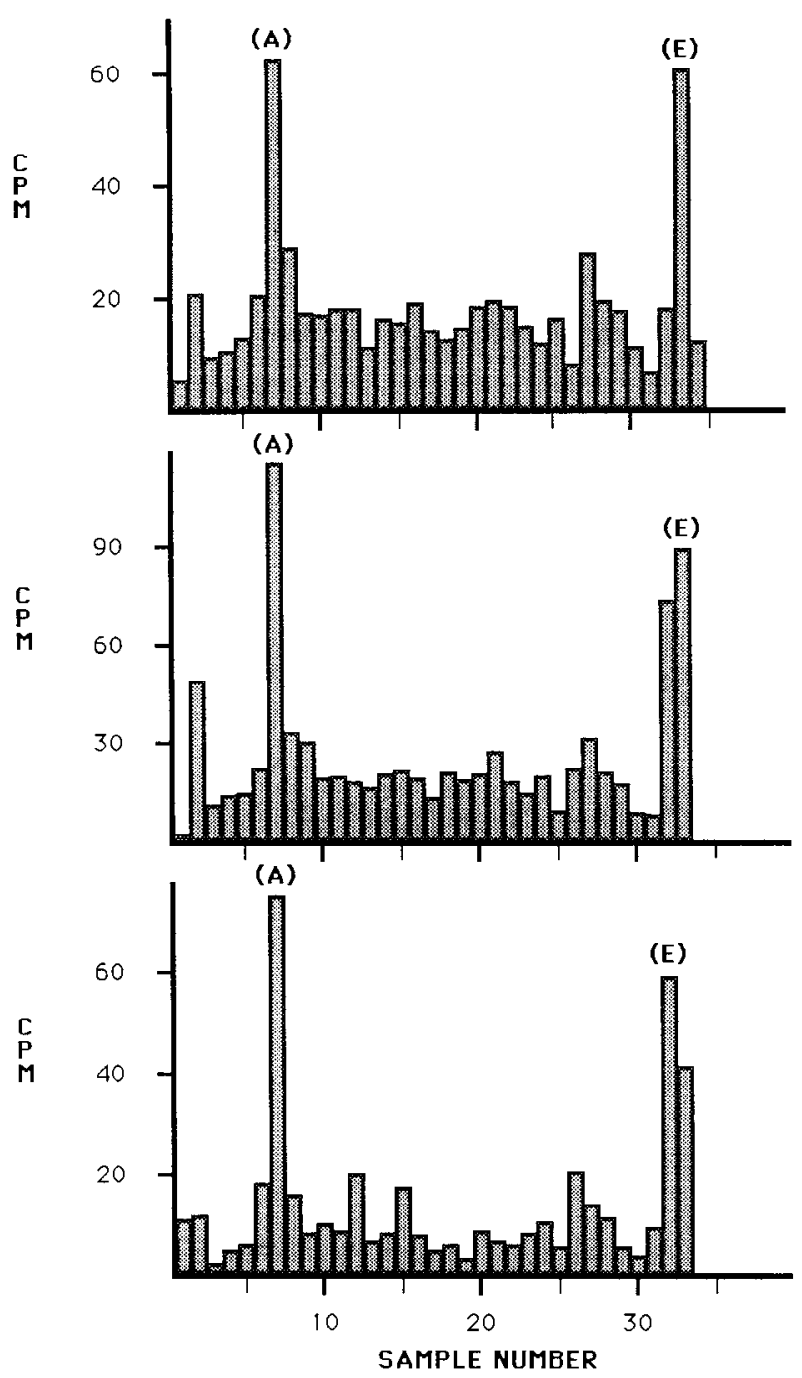

Figure 8. IEF profiles prepared from three individual bag cells taken from one bag-cell cluster are shown. Both ELH and AP are evident in each cell.

cells. It is well-cstablished that posttranslational modifications of membrane and secreted proteins begin in the cisternae of the endoplasmic reticulum, and continue in the Golgi sacs and membrane-bounded vesicles (Blobel, 1980; Palade, 1975; Rothman, 1981). With respect to cells that secrete more than one biologically active peptide, the location of the processing steps that separate one peptide from another could have regulatory implications. For example, if peptides are separated from one another prior to granule closure, regulation of granule contents could occur. Alternatively, if the major conversion steps in peptide production do not occur until granule closure, the peptide makeup of the secretory output of the cells will be essentially invariant. Given the evidence that ELH and AP are components of a common precursor (Arch et al., 1976 a, b; Berry, 1981; Berry et al., 1981; Mahon et al., 1985; Scheller et al., 1984; Yates and Berry, 1984), we predicted that secretory granules in axonal transport would show the same stoichiometry of ELH and AP as detected in the cell bodies at the end of a period of radiolabeled amino acid incorporation, if separation of these two peptides takes place intragranularly. The results of sampling the proximal, rostral neurites immediately after a $6 \mathrm{hr}$ pulse of labeling (Figs. 1-3) are not consistent with the prediction that cell body and neurite samples would show equivalent E:A stoichiometries. Moreover, the stoichiometry within the neurite

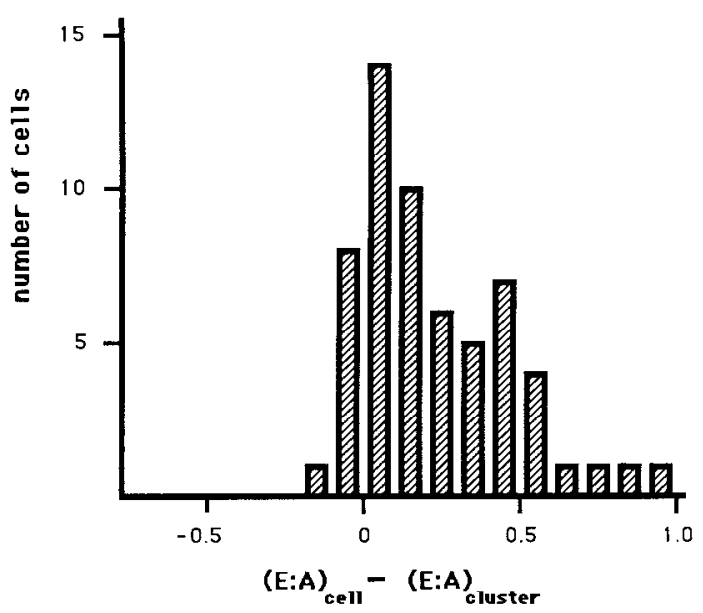

Figure 9. Frequency distribution of E:A ratios for 59 single bag cells is displayed. The values on the abscissa represent the difference betwecn the single cell ratio and that of the residual cell cluster. The width of the histogram bars was determined by the variability detected from assays of replicate samples.

fraction converges on the original soma value with increasing time after the end of radiolabel incorporation. This adjustment of labeled peptide representation in the neurites implies the existence of a process that compensates for the initial disproportion.

A possible compensating process, if precursor or common intermediate conversion is intragranular, could be a latency between AP and ELH production. If this were the case, an intermediate antecedent to ELH should be detectable in the neurite fractions. A candidate for this role could be the neutral species noted in the more rostral neuritic fractions illustrated in Figure 4 and also apparent in Figure 1, bottom. However, it would seem that the more rostral the sample, the longer the posttranslational interval available for conversion to have occurred; yet it is in these more rostral samples that the neutral species is most apparent. In any case, if a slowly converting intermediate for ELH were in transport, we would expect to see a trend toward decreasing quantities in the denominators of our neurite specific activity calculations (Fig. 2). As noted, these values do not show any trend. This suggests that the source of increasing representation of labcled ELH is the cell bodics and not conversion from species already in transport. We also performed the $1 \mathrm{hr}$ labeling pulse series to determine if the presumed latency between AP and ELH production could be observed at the time of initial precursor processing. The stability of the E:A ratio over the chase interval examined does not favor a hypothesis that AP is produced appreciably earlier than ELH.

An alternative to a latency in the sequential production of AP and ELH could be a more rapid turnover of AP than of ELH within the granule. For example, peptide mapping of the putative precursor (Berry et al., 1981) has indicated the presence of a second AP-like sequence. If both these APs are produced in the granule, but one is more liable to further processing, an initial disproportion between labeled AP and labeled ELH may be "corrected" over time as the more labile AP sequence is degraded. If this were the case, however, the course of specific activity change evidenced in Figure 2 would be expected to show a flat or eventually declining trajectory, depending on the relative kinetics of AP production and fractional degradation.

Another approach to evaluating a process of progressive AP degradation during transport is shown in our secretion studies. If the apparent relative increase in labeled ELH during chase is, in fact, a relative decrease of labeled AP, then by $24 \mathrm{hr}$ of chase, the peptides will have reached a point of equivalent ra- 
diolabeled stoichiometry in the neurites and terminals (Fig. 3). Hence, a secretory stimulus at this time should yield approximately equivalent amounts of labeled products in the medium. This prediction is not supported in our study (Fig. 5). There is a preponderance of labeled AP in the first secretion challenge to the tissue. Only on the second challenge to the same tissue do we see significant levels of labeled ELH. An inference from these results is that the initial disproportion of labeled AP in transport is sustained to the point of secretion $24 \mathrm{hr}$ later. Although this does not argue against intragranular degradation of either peptide, it does indicate that the time course of any such degradation is slow relative to the timing of our experiments.

The staging of secretion in accord with the presumed arrival time at the active secretory site implies the existence of some constraint on free intermixing of granules at the terminal. Although the manifestation of a queuing process is not consistent with the classical conceptions of random movement of secretory granules in the terminal cytoplasm, the likelihood that an ordering mechanism of some sort operates generally in peptidergic cells is implicit in the observation that more recently synthesized secretory peptides have a higher probability of being secreted than "older" molecules (e.g., Jamieson and Palade, 1971; Morrissey and Cohn, 1979; Nordmann and Labouesse, 1981; Sharoni et al., 1976). By comparison with the timing of studies in these other systems (typically many days), both labeled peptides in our samples would be considered "younger" products. Thus, it would appear that the queuing phenomenon operates on the more recently synthesized materials only.

The nature of the organizing mechanism is a matter of speculation; however, filamentous networks have been reported in both peripheral and central synaptic profiles in other preparations (Ellisman and Porter, 1980; Gray, 1978; Kondo et al., 1982; Stearns, 1982). The detailed cytoarchitecture, the relationships among the various elements, and the associations between any of these and secretory granules within terminals remain unresolved ( $c f$. Hirokawa et al., 1985). Nonetheless, even without active associations, the existence of a fibrous matrix within terminals might provide a passive restraining structure that would discourage rapid intermixing of granules. Our findings that colchicine and procaine treatments, immediately before secretion challenge, lead to evidence of granule intermixing are consistent with a hypothesis that polymerized and membrane-anchored fibrous elements play a role in secretory queuing.

The apparent difference in the kinetics of labeled AP entry into axonal transport and that of ELH is difficult to reconcile. The possibilities of a latency between AP and ELH production and a selective degradation of AP during transport are both unsupported. Our single-cell analyses also disfavor differential processing of precursors by different classes of bag cells, and are consistent with morphologic (Haskins et al., 1981), cytochemical (Smock and Arch, 1977), and immunohistochemical (Chiu and Strumwasser, 1981) studies indicating bag cell homogeneity. Consequently, it would appear that either ELH and AP are removed from their common precursor, or that they arise from different precursors before granule loading and are subsequently enclosed in newly formed granules at different rates. There is some ambiguity in published reports with respect to the origin of the AP species found prominently in the somata and neurites. Previous kinetic and quantitative data support the inference that it is derived from the same precursor as ELH. However, discrepancies in molecular weight estimates and amino acid content have appeared in the literature. The prominent $\mathrm{p} I 4.8$ species has been estimated to have a molecular weight in the range of 4900 Da by SDS-PAGE (Arch et al., 1976b), while the largest sequenced species with an appropriate isoelectric point is smaller by about $1500 \mathrm{Da}$ (Scheller et al., 1983). This difference may be the result of irregular migration on the gel system used however ( $c f$. Yates and Berry, 1981). A more serious challenge to the common precursor origin for ELH and AP is posed by the report, based on peptide mapping, that AP contains a methionine (Berry et al., 1981), while sequencing did not disclose a methionine in the putative AP (Scheller et al., 1983). Our approaches do not permit us to address the issue of AP origin directly; it is interesting to note, however, that the E:A ratio calculated for the cell somata at the end of the $6 \mathrm{hr}$ labeling pulse is $1.08 \pm 0.04$ (SEM). This is in rather close agreement with the value of 1.17 that would obtain (given leucine labeling) if the sequences for ELH and AP reported to be in the same gene were the ones we are following.

Our results show the passage of two peptides with the same "birthdates," irrespective of their common or disparate precursor origins, at different rates through the intracellular membrane systems of the bag cells. Since the BCO are known to be protein synthetically active in vitro for more than $48 \mathrm{hr}$, the presence of unlabeled ELH and AP is assumed in all samples. Hence, although of cell biologic interest, this kinetic difference in peptide processing under steady-state conditions may not have physiologic significance for the organism. Conversely, this phenomenon may indicate the presence of a regulatory window in which converting, sorting, or granulc-loading mcchanisms could operate to adjust the character of the secretory output of the bag cells in response to changes in the physiologic status of the organism.

\section{References}

Arch, S. (1972a) Polypeptide secretion from the isolated parietovisceral ganglion of Aplysia californica. J. Gen. Physiol. 59: 47-59.

Arch, S. (1972b) Biosynthesis of the egg-laying hormone (ELH) in the bag cell neurons of Aplysia californica. J. Gen. Physiol. 60: 102-1 19.

Arch, S. (1976) Neuroendocrine regulation of egg laying in Aplysia californica. Am. Zool. 16: 167-175.

Arch, S. (1981) Points of regulation in secretory peptide processing. In Neurosecretion: Molecules, Cells, Systems, D. Farner and K. Lederis, eds., pp. 129-137, Plenum, New York.

Arch, S., P. Earley, and T. Smock (1976a) Biochemical isolation and physiological identification of the egg-laying hormone in Aplysia californica. J. Gen. Physiol. 68: 197-210.

Arch, S., T. Smock, and P. Earley (1976b) Precursor and product processing in the bag cell neurons on Aplysia californica. J. Gen. Physiol. 68: 211-225.

Berry, R. (1981) Proteolytic processing in the biogenesis of the neurosecretory egg-laying hormone in Aplysia: I. Precursors, intermediates, and products. Biochemistry 20: 6200-6205.

Berry, R., M. Trump, and J. Baylen (1981) Proteolytic processing in the biogenesis of the neurosecretory egg-laying hormone in Aplysia: II. Analysis of tryptic fragments. Biochemistry 20: 6206-6211.

Blobel, G. (1980) Intracellular protein topogenesis. Proc. Natl. Acad. Sci. USA 77: 1496-1500.

Chiu, A., and F. Strumwasser (1981) An immunohistochemical study of the neuropeptidergic bag cells of Aplysia. J. Neurosci. 1: 812-826. Chiu, A., M. Hunkapiller, E. Heller, D. Stuart, L. Hood, and F. Strumwasser (1979) Purification and primary structure of the neuropeptide egg-laying hormone of Aplysia californica. Proc. Natl. Acad. Sci. USA 76: 6656-6660.

Dowdy, S., and S. Wearden (1983) Statistics for Research, Wiley, New York.

Ellisman, M., and K. Porter (1980) Microtrabecular structure of the axoplasmic matrix: Visualization of cross-linking structures and their distribution. J. Cell Biol. 87: 464-479.

Fletcher, D., J. Quigley, G. Bauer, and B. Noe (1981) Characterization of proinsulin- and proglucagon-converting activities in isolated islet secretory granules. J. Cell Biol. 90: 312-322.

Gainer, H., Y. Sarne, and M. Brownstein (1977) Biosynthesis and axonal transport of rat neurohypophysial proteins and peptides. $\mathbf{J}$. Cell Biol. 73: 366-381.

Glembotski, C. C. (1981) Subcellular fractionation on the posttranslational processing of pro-adrenocorticotropic hormone/endorphin in rat intermediate pituitary. J. Biol. Chem. 256: 7433-7439.

Gray, E. (1978) Synaptic vesicles and microtubules in frog motor endplate. Proc. R. Soc. London [Biol.] 203: 219-227. 
Gumbiner, B., and R. Kelly (1981) Secretory granules of an anterior pituitary cell line, AT-20, contain only mature forms of corticotropin and beta-lipotropin. Proc. Natl. Acad. Sci. USA 78: 318-322.

Haskins, J. T., C. H. Price, and J. E. Blankenship (1981) A light and clcctron microscopic investigation of the neurosecretory bag cells of Aplysia. J. Neurocytol. 10: 729-747.

Herbert, E., N. Birnberg, T. Lissitsky, O. Civelli, and M. Uhler (1981) Pro-opiomelanocortin: A model for the regulation of expression of neuropeptides in pituitary and brain. Neurosci. Comment. 1:16-27.

Hirokawa, N., G. Bloom, and R. Vallee (1985) Cytoskeletal architecture and immunocytochemical localization of microtubule-associated proteins in regions of axons associated with rapid axonal transport: The $\beta, \beta^{\prime}$-iminodipropionitrile-intoxicated axon as a model system. J. Cell Biol. 101: 227-239.

Hook, V., and Y.-P. Loh (1984) Carboxypeptidase B-like converting enzyme activity in secretory granules of rat pituitary. Proc. Natl. Acad. Sci. USA 81: 2776-2780.

Jamieson, J., and G. Palade (1971) Synthesis, intracellular transport, and discharge of secretory proteins in stimulated pancreatic exocrine cells. J. Cell Biol. 50: 135-158.

Kondo, H., J. Wolosewick, and G. Pappas (1982) The microtrabecular lattice of the adrenal medulla revealed by polyethylene glycol embedding and stereo electron microscopy. J. Neurosci. 2: 57-65.

Kupfermann, I. (1972) Stimulation of egg-laying by extracts of neuroendocrine cells (bag cells) of abdominal ganglion of Aplysia. J. Neurophysiol. 33: 877-881.

Loh, Y., Y. Sarne, and H. Gainer (1975) Heterogeneity of protein synthesized, stored, and released by the bag cells of Aplysia californica. J. Comp. Physiol. 100(B): 283-295.

Mahon, A., J. Nambu, R. Taussig, M. Shyamala, A. Roach, and R. Scheller (1985) Structure and expression of the egg-laying hormone gene family in Aplysia. J. Neurosci. 5: 1872-1880.

Morrisscy, J., and D. Cohn (1979) Secretion and degradation of parathormone as a function of intracellular maturation of hormone pools. J. Cell Biol. 83: 521-528.

Nicholson, G., V. Smith, and G. Poste (1976) Effects of local anesthetics on cell morphology and membrane-associated cytoskeletal organization in BALB/3T3 cells. J. Cell Biol. 68: 395-402.

Nordmann, J., and J. Labouesse (1981) Neurosecretory granules: Evidence for an aging process within the neurohypophysis. Science 211 : 595-597.
Palade, G. (1975) Intracellular aspects of the process of protein synthesis. Science 189: 347-358.

Rothman, B., R. Scheller, and E. Mayeri (1985) The bag cells of Aplysia as a peptidergic multi-transmitter system: From genes to behavior. In Gene Expression in Brain, C. Zomzely-Neurath and W. Walker, eds., pp. 235-274, Wiley, New York.

Rothman, J. (1981) The Golgi Apparatus: Two organelles in tandem. Science 213: 1212-1219.

Scheller, R., J. Jackson, L. McAllister, J. Schwartz, E. Kandel, and R. Axel (1982) A family of genes that codes for ELH, a neuropeptide eliciting a stereotyped pattern of behavior in Aplysia. Cell 28:707719.

Scheller, R., J. Jackson, L. McAllister, B. Rothman, E. Mayeri, and R. Axel (1983) A single gene encodes multiple neuropeptides mediating a stereotyped behavior. Cell 32: 7-22.

Scheller, R., R.-R. Kaldany, T. Kreiner, A. Mahon, J. Nambu, M Schaefer, and R. Taussig (1984) Neuropeptides: Mediators of behavior in Aplysia. Science 225: 1300-1308.

Sharoni, Y., S. Eimerl, and M. Schramm (1976) Secretion of old versus new exportable protein in rat parotid slices. J. Cell Biol. 71: 107-122.

Smock, T., and S. Arch (1977) A cytochemical study of the bag cell organs of Aplysia californica. J. Histochem. Cytochem. 25: 13451350.

Stearns, M. (1982) High voltage electron microscopy studies of axoplasmic transport in neurons: A possible regulatory role for divalent cations. J. Cell Biol. 92: 765-776.

Stuart, D., A. Chiu, and F. Strumwasser (1980) Neurosecretion of egg-laying hormone and other peptides from electrically active bag cell neurons of Aplysia. J. Neurophysiol. 43: 488-498.

Ward, S., D. Wilson, and J. Gilliam (1970) Methods for fractionation and scintillation counting of radioisotope-labeled polyacrylamide gels. Anal. Biochem. 38: 90-97.

Yates, M., and R. Berry (1981) Limited heterogeneity of ncurosecretory proteins produced by the bag cells of Aplysia. Gen. Comp. Endocrinol. 43: 308-314.

Yates, M., and R. Berry (1984) Subcellular sites of processing of precursors to neurosecretory peptides in the bag cells of Aplysia: Inferences from the effects of monensin, FCCP, and chloroquine. J. Neurobiol. 15: 141-155. 